This is probably the first case of its kind reported in this country.

A careful review of the literature of the subject reveals several cases on record abroad in which placental tissue was undoubtedly attached to the cervix.

I. Mäller has reviewed the literature, but without finding cases in which the anatomic investigntions were thorough enough to assure the correctness of the diagnosis.

In more recent years several cases have heen reported which are so convineing in their clinical and anatomice aspects that the occasional existenere of a placenta previa cerviealis camnot lomger be doubted.

Dr. Otto y. Weiss ${ }^{1}$ reported a case of a quintipara. aged 33, who was admitted at full term on acconnt of profuse henorrhage, witl a diagnosis of placenta pravia. Tamponade was followed by polalic version and delivery, with the loss of a large amount of blood. The child died during the attempt at delivery. 'The placenta was found intimately allorent to the cervieal mucous nombrane and was separated from it with great difficulty by manual extraction. $A$ chill and fever oceurred and it was found that there was a streptorocens infection with retained slureds of placenta. Vaginal hysterectomy was followed by death on the third day.

A. Keilnamn² reported a case of a tertipara armitted with ruptured membranes, slight labor pains and some hemorrhage. Spontaneous delivery oceurred. 'Two hours later a portion of undelivered placenta was found adherent to the anterior lip of the cervix and was removed with great difficulty by manual seinaration.

E. Ponfick ${ }^{3}$ reported a case of a nonipara with repouted hemorrhages during prognaner. A dingnosis of placenta pravia was made and on the left and posterior aspect. the placenta was found to be continued down inseparably adherent as far as the vnginal pottion of the cervix.

Jaschaci rejorts a recent case of placenta isthmica et cervicalis.

The cases which have been so far reported in the literature have not been supportel by microscopic evidence and are so few in number as to warrant the assumption that placenta pravin cervicalis is either a very rare condition or one which is very rurely recognized.

$$
\text { 669 Madison Aventue. }
$$

\section{SUBPARIETAL RUPTURE OF SOLITARY KIDNEY *}

\section{A. J. MAYER, M.D., $†$ AND A. NELKEN, M.D. NHW OR1,EANS}

The horseshoc kidney, while rare, is sufficiently common to require no especinl comment. Those anomalous conditions in which the kidneys are completely fused into one mass are of much less common occurrence. To this condition, the Kuchinniere of the Germans, Rokitansky applied the term "solitary kidney" to differentiate it from the true single, or "unsymmetrical" kidney.

Morris, reviewing the statistical reports of four of the largest of the London hospitals, found that while the "horse-shoe" kidney was present once in each 1,000

1. Weiss: Centrulbl, f. (Gynce., 1897, p. 641.

2. Kellmann : Cent'ultil. G. Gynec. 1897 , p. 857.

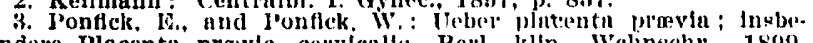
sondere Placenti provla cervicalis, Berl. klin. Welinschr., 1809, No. 35 .

4. Jaschke: Ztselur. f. Gynec., Mnreh, 1911, 1. 1409.

lathologic report by 15.

t Uicensed, Jan. 14, 1011 . autopsies, the fused kidney, not of the "horseshoe" variety, was found only once in 15,908 necropsies.

Subparietal rupture of the kidney is comparatively rare. Connell, in a paper read before the Western Surgical Association, ${ }^{1}$ collected from all sources a total of $8+1$ cinses.

Our case of subparietal rupture of a "solitary" kidnes" is, we believe, unique in the literature.

Hisfory-Our patient was a white man, 30 ycurs of age, a native of England, and $n$ anilor by oceupation. We were umble to get $n$ connected recount of his injury and the sequelax, lut, as fur as we were able to gather, seven day prior to npplying for treatment, while climbing a ladder, he lud fullen 4 distunce of from four to six feet. In falling har body swung around, und he struck with his right lumbar reuion on an iron rail. Je complained of some pain in his right side, following the injury. but continned to void urine Iip to seven days ufter the necident. lle were unable to len whether or not this urine eontuined blood. His urine stopping sudlenly (?), the cuptuin of his ship sent him to the Touro for treatment.

Examination.-The patient was almitted to the service of Dr. Matas who requested Dr. Mayer to look after him. On admission the putient's general condition was good, his tem perature was normal. He showed considerable ecchymosis in the right lumbar region and in the perinem. A large diffuse swelling could he folt in the right side almost to the umbilicus, and longrudinally from the last rib to the pelvis. The aldomen was distended and very tense. About two ounees of bloody urine were witlidrnwn by cutleter. He was entleterized twice more in the following twenty-four hours, lut no uring was olituined. He vomited three times the day following admission.

bragnesis.-The question of dingnosis was interesting. The history of the injury and the mass in the right side suggested at once rupture of the right kidney. But rupture of the right, kidney would not explain the absence of urine in the bladder, since tlepe was no evidence of damage to the left kidney linpture of the bludder, with postperitoneal infltration of urine was contra-indicated by the nature of the injury, and especially, by the fact that the patient had voided urine no mally for scven days after the necident.

'The possibility' of there being but one kidney was discussed, but, if this race nomaly was present, we could not explaint why a ruptured single kishey should secrete what the patient described as being compuratively normal urine for seven daght and then suddenly cense functioning. lupture of the rigen. kidney, with subsequent sloughing of the bladder-wall, the the son for which we did not understund, seemed to us to

unly plausible explanation of the conditions present. of the

Because of this opinion, and because the condition of that patient did not justify any unnecessary delay, no attempt nt cystoscopy was mude. As was demonstruted by subsequend findings, cystoscopy with catheterizution of the ureters woled lave been unintelligilble or even misleading, unlese catheters had been used and a radiogruph taken.

Operation-At Dr. Natas' sugyestion, un exploratory lapa. rotomy was done. The incision was made to the left of the median line, to avoid possible contaminution of the periton the cavity with what appeared to be inflitruted urine beneath was abiominal wall on the right side. When the peritoneum clear opened, the cuvity was found to contain nbout a pint of ceal, fluid which had no urinury odor. To the right, postperitona a extending from the last rib to the crest of the ilium widney. large oval swelling which evidently included the right made $^{\text {s }}$ No left kidney could te found, although senrch was made was high as the spleen and as low as the pelvis. The bladder was tested and found to be intuct. The abdominal wound istion elosed with some difficulty because of the intestinal distentions and the putient turned over on his left side. The ordiscles loin incision was made over the right kidney. As the murine. were being cut through there was a gush of bloong The kid. The wound was enlarged and the hand introduced.

1. Connell : The Jounsal A. A Jurch 25,1911, p. 875 . 
wise was found to be lying slightly lower than usual, but other. was roughity was normal. The lower pole of the kidney kidney partially organiled with what seemed to be sloughing tissue and and considerabized blood-clots. 'The ureter was felt to be lard of the ureter $A_{B}$ the or of the pelvis of the kilney.

in careful examition of the patient was bad, no time was lost done, the examination. Drainnge with tubes and gauze was ward. Shound dressed, and the patient was returned to the and he conting after the operation, the patient voided urine, he never rallied to void normal quantities of clear urine. But thereafter.
thed from the operation, and died thirty-six hours

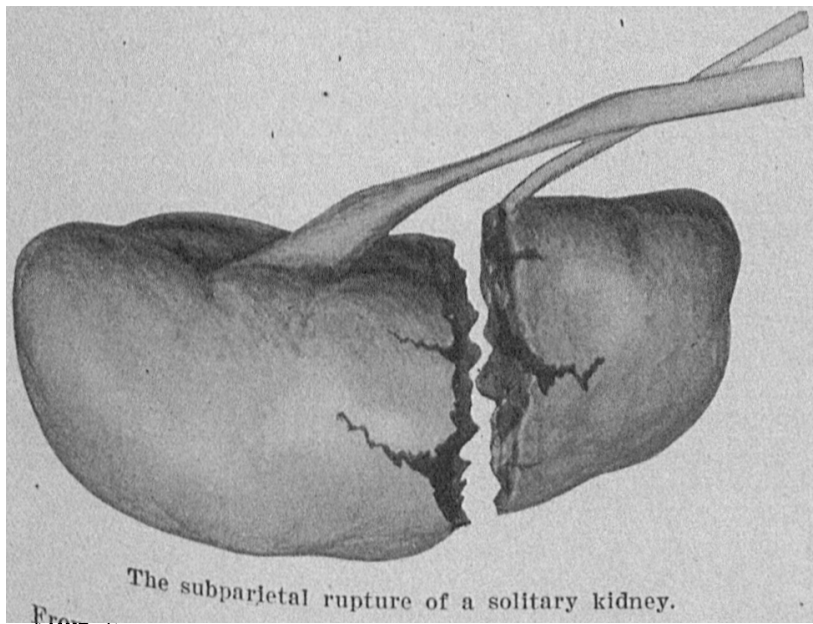

the in the findings at atupsy, we concluded that, following function un to the kiduey, the upper segment continued to completely until the grudually contracting blood-clot finally kidhe operation, by the ureter.

kidney to resum, by removing the obstruction, permitted the

at there rume its function. The autopsy findings showed is The autopey been no hydronephrosis.

appended. was performed by Dr. F. B. Gurd, whose report Autop

eral examinh -This was performed six hours after death; a genWith the excention of the body revenled nothing worthy of note right kidney. Over they.

length, the loin on the right side is an incision $10 \mathrm{~cm}$. in the mid-line a second incision of a similar length opening into above the pubis. to

to be deeng the abdomen, the posterior peritoneum appears thing behind redish-black in color, the result of a blood-clot blo neighborho it. This appenrance is especially marked in is ood.clot, which of the right kidney. Separation of this the moderately mensures from 2 to $6 \mathrm{~cm}$. in thickness and normight kid friable, deep red in color and firm, discloses aboully firm. This organ is large (weight $380 \mathrm{gm}$.) and ave down. Somewhat below the center of the organ from sparated surf there has been a solution of continuity, the apace being fulles lying about $4 \mathrm{~cm}$. apart, the intervening parently filled with blood-clot and greyish friable masses, 0 n the necrotic material.

kiding them in of the two portions of the kidney and the with is seen opposition, a more or less normal shaped lurge rupt the excep. 'The surface is smootl and normal in color, upture. In thon of an nrea $2 \mathrm{~cm}$. wide on either side of the gener-yellow zones the surface is mottled deep red and cut more in color. On section the organ appears in thicurface or less normal, though somewhat pale. The glomened, meases and exudes fluid blood. The cortex is bifferuli are soring from 0.0 to $0.8 \mathrm{~cm}$. in diameter. The well tentiation somewhat more distinctly prominent than usual. of marked between the cortex and medulla is moderately the line. The central portion of the kidney on either side of rupture shows irregular deep purple, somewhat softer areas between which lie triangular yellowish portions with the apex pointing toward the medulla. These areas correspond to yellowish blotches seen on the surface.

At the point mentioned, namely $4 \mathrm{~cm}$. from the kidney, the ureter is constricted mensuring not more than $0.35 \mathrm{~cm}$. in diameter for $a$ distance of $4 \mathrm{~cm}$. The wall of this ureter throughout its entire length is somewhat thickened.

The second ureter which is approximately half the size of the other arises from the lower portion of the kidney, at the point of rupture. No pelvis, and no calices are present.

'lwo sets of blood-vessels supply the kidney. One in the neighborhoorl of the upper, the other in the neighborhood of the lower ureter.

Absolvicly no evidence of a second or left kidney can be foumls.

'The bludder eontains two normal-looking ureteral openings, the left opening being silunted slightly further from the urethral opening than the right, giving the trigone an irregular appearance. The two ureters cross one another about 8 cil. above the bifurention of the aorta, the right going to the upper pole of the kidney and the left to the lower. On removal, the kidney is found to weigh $400 \mathrm{gm}$., and, though large when the two portions are approximated, is normal in size. The kidney substunee is moderately firm and somewhat paler than normal. On the upper surface of the lower portion several irregular, yellowish blotches are noted.

Anutomir Diagnosis: Congenital absence of left kidney; traumatic rupture of right kidney, retroperitoneal hematoma (perirenal).

Ificroscopic Fxamination of Kidncy: A section cut from a more normal-looking area of the kidney shows an injection of the renal vessels and a few sclerosed Malpighian tufts. 'The cells lining the tubules are somewhat swollen and take the rel stain with molernte intensity. The nuclei stain well. Within the tubules and about the glomeruli there is a modcrate amount of granular red staining material (serum).

Other sections cut from the greyish purple area in the line of rupture consist of blood-clot, made up chiefly of necrotic blond-rells and kidney substance infiltrated here and there with polymorphonuclear leukocytes.

Section 3 cut from one of the yellowish nodules in the lower portion shows a necrosis in situ of the kidney substance surrounded by a zone characterized by injection of the blood. vessels and interstitial exudnte of serum.

Misroscopio Diagnosis: Acute nephritis

Infarets of the kidney (traumatic).

Perrin J3uilling.

\section{A NEW BLOOD-VESSEL FORCEPS BER'TRAM M. BERNHEIM, M.D. BALTIMORE}

The slightest scrateh given the intima during the manipulations required in any blood-vessel work almost invariably spells failure in the form of a thrombus. Sharp-pointed instruments are, therefore, scrupulously avoided in all such work: Indeed, most men find their fingers the best and safest of all instruments.

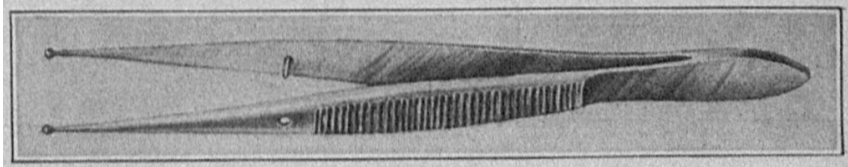

Blood-vessel forenps, with small ball-tlpped ends

But since the work can at times be facilitated by a delicate pair of forceps, I have had one constructed which has a small, polished metal knob about the size of an ordinary pin-head on each end. These knobs enable one to grasp the vessel firmly without doing the sligrlutest damage to the intima.

2319 linden Avonue. 